\title{
ECC
}

\section{Simultaneous determination of levodopa and tryptophan using a modified glassy carbon electrode}

\section{Mohammad Reza Aflatooniana,b, Somayeh Tajik,c,*, Behnaz Aflatoonianc, Mehri-Saddat Ekrami-Kakhkid, Kouros Divsalara, Iran Sheikh Shoaiee, Zahra Dourandishe, Mahdieh Sheikhshoaief}

${ }^{a}$ Neuroscience Research Center, Kerman University of Medical Sciences, Kerman, Iran

${ }^{b}$ Leishmaniasis Research Center, Kerman University of Medical Sciences, Kerman, Iran

${ }^{c}$ Research Center for Tropical and Infectious Diseases, Kerman University of Medical Sciences, Kerman, Iran

'Esfarayen University of Technology, Esfarayen, Iran

eDepartment of Chemistry, Faculty of Science, Shahid Bahonar University of Kerman, Kerman 76175-133, Iran

fDepartment of Mining Engineering, Shahid Bahonar University of Kerman, Kerman, Iran

Received: 18 June 2019, Accepted: 04 December 2019, Published: 15 December 2019

\begin{abstract}
This work discusses the development of a new sensor for simultaneous determination of levodopa and tryptophan. The proposed sensor was a glassy carbon electrode modified with $\mathrm{V}_{2} \mathrm{O}_{5}$ nanoparticles. Based on the excellent electrochemical properties of the modified electrode, a sensitive voltammetric method was used for individual and simultaneous determination of the levodopa and tryptophan in the aqueous solutions. The proposed method under the optimized conditions was utilized to determine the levodopa with linear range of $0.06-250.0 \mu \mathrm{M}$ and detection limit of $0.02 \mu \mathrm{M}(\mathrm{S} / \mathrm{N}=3)$. Finally, the applicability of the proposed sensor was verified by evaluation of levodopa and tryptophan in real sample.
\end{abstract}

Keywords: Levodopa; tryptophan; $\mathrm{V}_{2} \mathrm{O}_{5}$ nanoparticles; glassy carbon electrode.

Introduction

Levodopa

$((-)-3-(3,4-$

dihydroxyphenyl)-l-alanine, L-dopa) is an important chemical substance and a naturally occurring dietary supplement and psychoactive drug found in certain kinds of food and herbs and is synthesized from the essential amino acids 1-phenylalanine and 1-tyrosine in the mammalian body and brain [1]. Levodopa medication has been used for the most commonly prescribes for
Parkinson's disease. People with Parkinson's disease have depleted levels of dopamine, causing tremor, muscle stiffness or rigidity, slowness of movement (bradykinesia) and loss of balance. Since Dopamine cannot be administered directly as it does not cross the blood brain barrier readily, while after oral administration, levodopa is absorbed and converted into dopamine by decarboxylase. Therefore, levodopa can alleviate the

*Corresponding author: Somayeh Tajik

Tel: +98 (913) 1965532, Fax: N/A

Eurasian. Chem. Commun. (2020) 505-515

E-mail: tajik_s1365@yahoo.com 
symptoms of Parkinson's disease, decreasing the muscular rigidity and tremors [1].

Tryptophan (TRP, 2-amino-3-(1Hindol-3-yl)-propionic acid), a vital constituent of proteins and a precursor for biologically important molecules such as the neurotransmitter serotonin, dopamine and the neurohormone melatonin. Moreover, it is an indispensable component in human nutrition for building and keeping a positive nitrogen balance. Since TRP is not synthesized by the human organism and is not found in significant amounts in vegetables, it may be administered in the form of medications and food supplements [2]. TRP is one of the main components of drugs used to treat disorders such as depression and hypertension. Nonetheless, its improper metabolization has been suggested to be a possible cause of schizophrenia, hallucinations, and delusions, due to the formation of a toxic metabolite in the brain. Furthermore, high dosages of TRP can cause nausea, dizziness, and loss of appetite [3].

According to the above mentioned content and since supplementation may be beneficial for patients receiving levodopa, competition between tryptophan and levodopa may result in tryptophan malabsorption, leading to depression and other side effects of levodopa treatment. So, it is necessary and important for simultaneous determination of the levodopa and tryptophan in pharmaceutical and biological samples.

A variety of analytical methods such as spectrophotometry [4,5], capillary electrophoresis [6,7], and chromatography methods $[8,9]$, have been developed to measure the levodopa and tryptophan levels in different sample matrices. However, these methods are sometimes unsuitable for routine analysis due to the requirement of expensive instruments, long analysis time, and sample pretreatment. Moreover, due to the electroactive properties of levodopa and tryptophan, those can be determined by electrochemical methods. Electrochemical technique is a good alternative to the aforementioned methods due to the faster response, higher selectivity, higher sensitivity, reproducibility, easy operation and lower cost [10-14].

Glassy carbon electrodes (GCEs) are very versatile as electrode material for trace level determination of organic molecules as they provide high sensitivity, negligible porosity, and good mechanical rigidity. Bare glassy carbon electrodes have always suffered from serious problems such as interference and electrode fouling, which can result in poor selectivity and reproducibility [15-17]. To resolve these problems, chemically modified electrodes (CME) with various materials have emerged as efficient and versatile approach and attracted considerable interest over the past two decades due to the advantages in terms of reduced costs, automatic and fast analysis, high sensitivity and selectivity [18-21].

The unprecedented achievements in nanoscience and nanotechnology in the recent era has strongly urged the researchers to integrate the nanomaterial in electrode fabrication to achieve an ultrasensitive surface with improved selectivity. The reasons for their growing applications relates to their unique physical and chemical properties which entirely different from their bulk counterparts. Through different synthetic routes, it is now possible to develop nano-scaled materials with highly controlled shape, 
surface area, size, charge and physicochemical properties [23,24].

Vanadium oxide $\left(\mathrm{V}_{2} \mathrm{O}_{5}\right)$ is the most stable oxide with semiconductor property and the energy gap of $\sim 2.2 \mathrm{eV}$ at room temperature. $\mathrm{V}_{2} \mathrm{O}_{5}$ is of instance interest due to its layered structure, various phases, great catalytic, good electrical and optical properties. Layered structure and special characteristics (chemical sensing and electrochemical properties) of $\mathrm{V}_{2} \mathrm{O}_{5}$ has attracted much interest. The good catalytic activity is the result of easy reduction and oxidation between the multiple oxidation states of vanadium in the $\mathrm{V}_{2} \mathrm{O}_{5}$. It was recently reported that $\mathrm{V}_{2} \mathrm{O}_{5}$ possess electrocatalytic activity, where $\mathrm{V}^{5+}$ ions play the dominant role for the electrooxidation reaction [25-27]. In the light of the above information, this work aims at developing a modified electrode for the sensitive determination of levodopa and tryptophan, using $\mathrm{V}_{2} \mathrm{O}_{5}$ nanoparticles to enhance the properties of glassy carbon electrodes. The resulting electrode is successfully applied for the determination of levodopa and tryptophan in the real samples.

\section{Experimental}

Apparatus and Chemicals

An Autolab potentiostat/galvanostat (PGSTAT 302N, Eco Chemie, the Netherlands) was applied to measure the electrochemicals. General Purpose Electrochemical System (GPES) software was employed to control the conditions of experiments. A conventional three-electrode cell was used at $25 \pm 1{ }^{\circ} \mathrm{C}$. An $\mathrm{Ag} / \mathrm{AgCl} / \mathrm{KCl}$ $(3.0 \mathrm{M})$ electrode (Azar Electrode, Urmia, Iran), a platinum wire (Azar Electrode, Urmia, Iran), and the $\mathrm{V}_{2} \mathrm{O}_{5} / \mathrm{GCE}$ were used as the reference, auxiliary and working electrodes, respectively. $\mathrm{pH}$ was measured by a
Metrohm $710 \mathrm{pH}$ meter. Levodopa, tryptophan, and all the remaining reagents had an analytical grade. They have been prepared via Merck (Darmstadt, Germany). Orthophosphoric acid and the related salts that were above the $\mathrm{pH}$ range of 2.0-9.0 were used for preparing the buffer solutions. $\mathrm{V}_{2} \mathrm{O}_{5}$ nanoparticles were synthesized in our laboratory as reported previously [27].

\section{Preparing electrode}

$\mathrm{V}_{2} \mathrm{O}_{5}$ nanoparticles have been used to coat the bare glassy carbon electrode. A stock solution of $\mathrm{V}_{2} \mathrm{O}_{5} / \mathrm{GCE}$ in $1 \mathrm{~mL}$ of aqueous solution has been prepared by distributing $1 \mathrm{mg}$ of $\mathrm{V}_{2} \mathrm{O}_{5}$ nanoparticles via ultra-sonication for $30 \mathrm{~min}$, whereas $5 \mu \mathrm{L}$ of aliquots of the $\mathrm{V}_{2} \mathrm{O}_{5}$ nanoparticles suspension solution has been cast on carbon working electrodes. Then, we waited until the solvent evaporation at room temperature.

\section{Preparing real samples}

Samples of urine have been kept in a refrigerator directly after gathering. Ten millilitres of samples have been centrifuged for fifteen minutes at 2,000 rpm. The supernatant has been filtered by a $0.45 \mu \mathrm{m}$ filter. Next, various volumes of solution has been transported into a 25 millilitres volumetric flask and diluted to the mark with PBS $(\mathrm{pH}=7.0)$. This diluted urine samples were anaesthetized with different amounts of levodopa and tryptophan. Content of levodopa and tryptophan have been analyzed using the suggested procedure by employing the standard addition method.

\section{Result and discussion}

Characterization of $\mathrm{V}_{2} \mathrm{O}_{5} / \mathrm{NPS}$

The morphology of $\mathrm{V}_{2} \mathrm{O}_{5} / \mathrm{NPs}$ was assessed using scanning electron microscope (SEM). Figure 1 reveals the typical SEM images of the $\mathrm{V}_{2} \mathrm{O}_{5} / \mathrm{NPs}$ sample. It was found that the 
synthesized $\mathrm{V}_{2} \mathrm{O}_{5} / \mathrm{NPs}$ have a spherical shape with diameter $\sim 35 \mathrm{~nm}$.

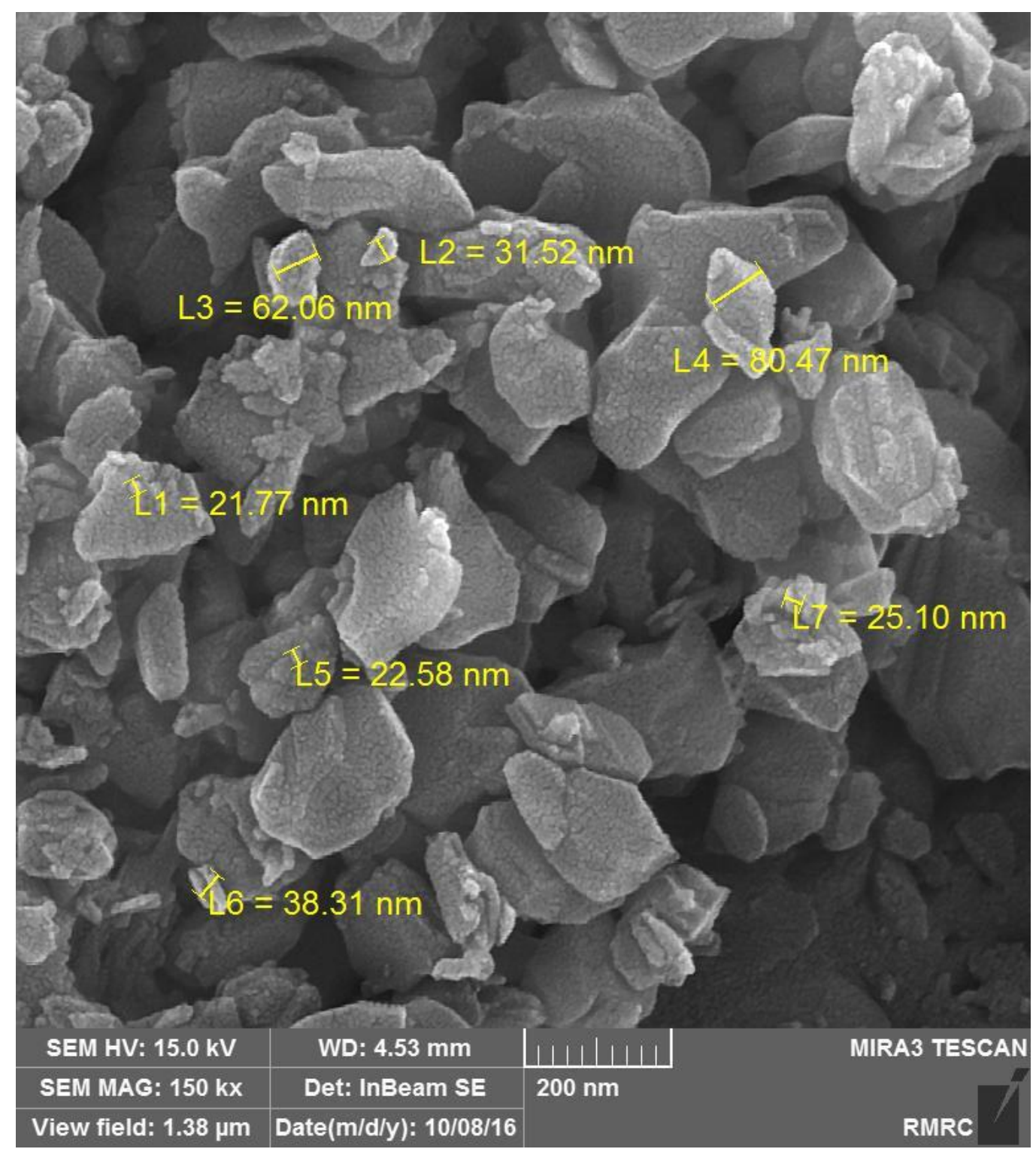

Figure 1. SEM image of $\mathrm{V}_{2} \mathrm{O}_{5}$ nanoparticles

\begin{tabular}{|c|c|}
\hline Electrochemical & $\mathrm{pH}<9.0)$ at the surface of $\mathrm{V}_{2} \mathrm{O}_{5} / \mathrm{GCE}$ by \\
\hline levodopa on $\mathrm{V}_{2} \mathrm{O}_{5} / \mathrm{GCE}$ surface & found \\
\hline The electrochemical behaviour of & electrocatalytic oxidation of levodopa \\
\hline levodopa is dependent on the $\mathrm{pH}$ value & at the surface of $\mathrm{V}_{2} \mathrm{O}_{5} / \mathrm{GCE}$ was more \\
\hline of the aqueous solution (Figure 2). & favoured under neutral conditions than \\
\hline Therefore, $\mathrm{pH}$ optimization of the & cidic or basic medium, because the \\
\hline solution seems to be necessary in order & obtained current was more than other \\
\hline to obtain the electrocatalytic & $\mathrm{pH} 7.0$ was chosen as \\
\hline of levodopa. Thus the electrochemical & the optimum $\mathrm{pH}$ for electrocatalysis of \\
\hline behaviour of levodopa wa & the surface of \\
\hline $0.1 \mathrm{M}$ PBS in different $\mathrm{pH}$ va & ${ }_{2} \mathrm{O}_{5} / \mathrm{C}$ \\
\hline
\end{tabular}


<smiles>NC(CC1=CC(=O)C(=O)C=C1)C(=O)O</smiles>

Figure 2. Electrochemical oxidation of levodopa

Figure 3 shows responses of $\mathrm{CV}$ to electro-oxidation of $100.0 \mu \mathrm{M}$ levodopa at the unmodified GCE (curve b) and $\mathrm{V}_{2} \mathrm{O}_{5} / \mathrm{GCE}$ (curve a). The peak potential occurs at $350 \mathrm{mV}$ due to levodopa oxidation, which is around $300 \mathrm{mV}$ more negative than the unchanged GCE. Furthermore,
$\mathrm{V}_{2} \mathrm{O}_{5} / \mathrm{GCE}$ exhibits very high anodic peak currents for levodopa oxidation than that of the unchanged GCE. This showed a significant improvement of the electrode performance toward levodopa oxidation by changing the constant GCE with $\mathrm{V}_{2} \mathrm{O}_{5}$ nanoparticles.

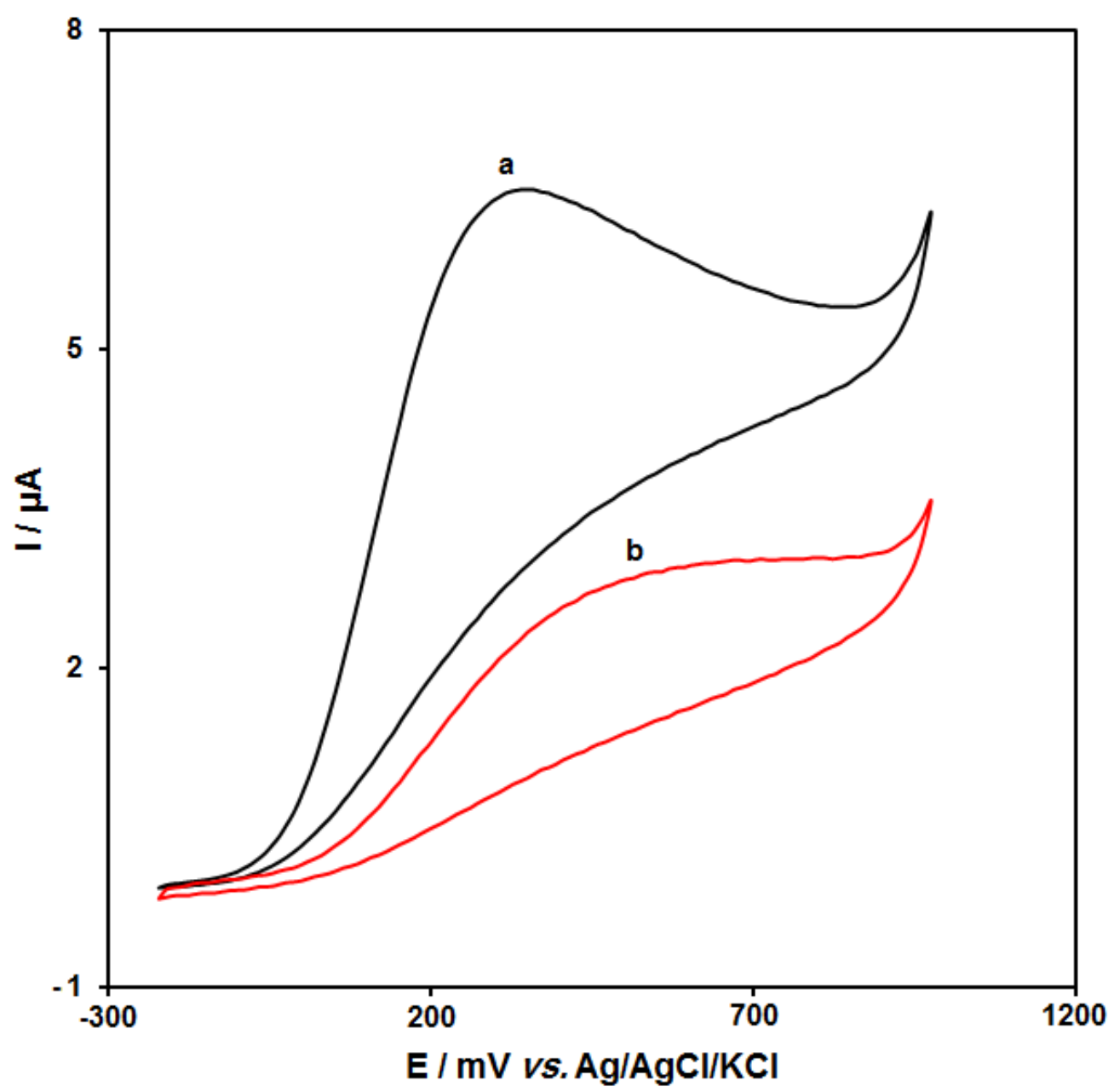

Figure 3. CVs of a) $\mathrm{V}_{2} \mathrm{O}_{5} / \mathrm{GCE}$ and b) unmodified GCE in the presence of $100.0 \mu \mathrm{M}$ of levodopa at $\mathrm{pH}$ 7.0. In all cases, the scan rate was $50 \mathrm{mV} \mathrm{s}^{-1}$ 


\section{Effect of scan rate}

Researchers investigated the impact of the rates of potential scan on levodopa oxidation current (Figure 4). Findings indicated induction of enhancement in the current of the peak by the increased potential scan rate. Additionally, diffusion in oxidation processes are monitored, as inferred by the linear dependence of the anodic peak current (Ip) on the square root of the potential scan rate $\left(v^{1 / 2}\right)[28]$.

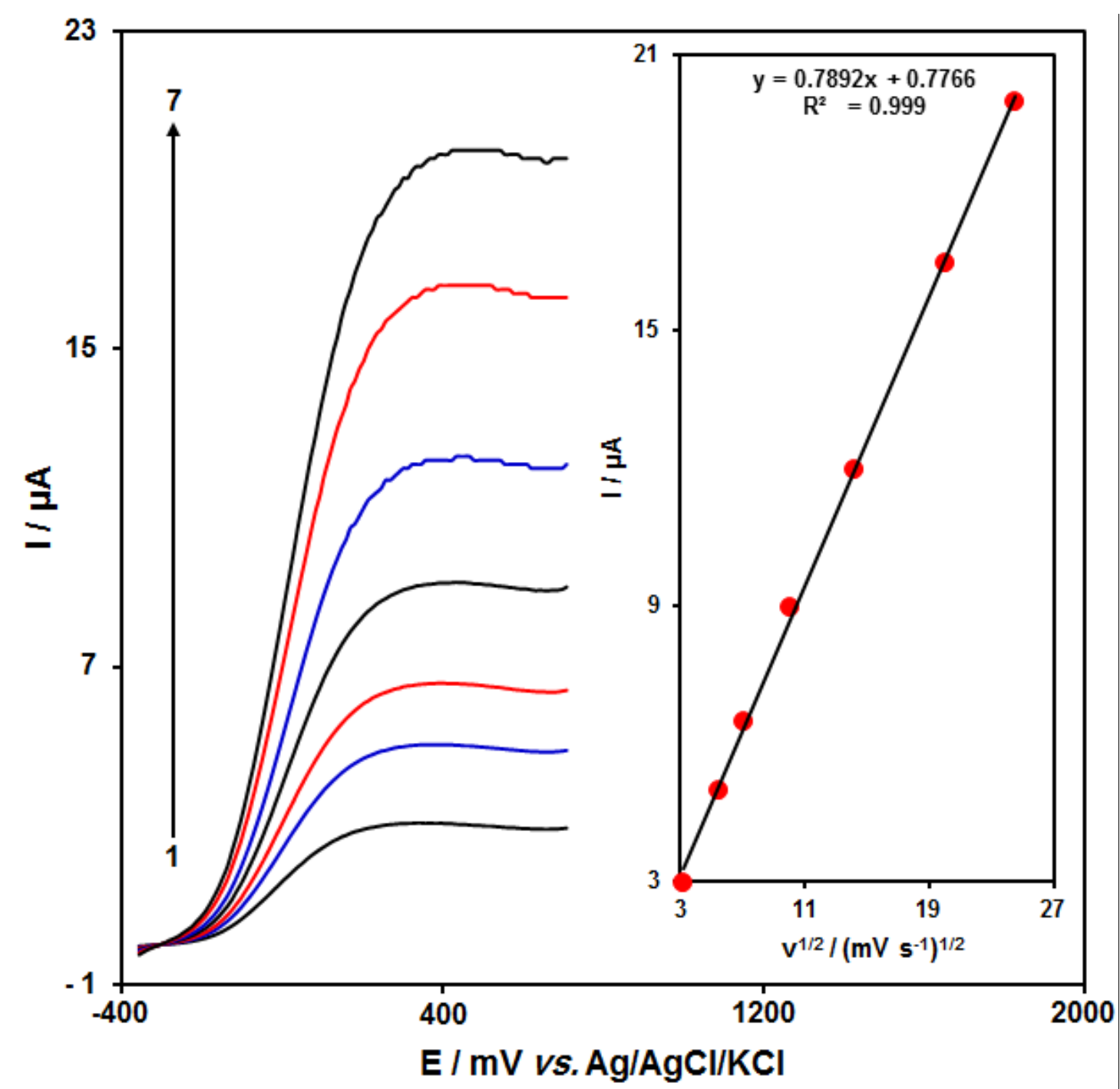

Figure 4. $\mathrm{LSVs}$ of $\mathrm{V}_{2} \mathrm{O}_{5} / \mathrm{GCE}$ in $0.1 \mathrm{M}$ PBS ( $\mathrm{pH}$ 7.0) containing $100.0 \mu \mathrm{M}$ of levodopa at various scan rates; numbers $1-7$ correspond to $10,30,50,100,200,400$ and $600 \mathrm{mVs}^{-1}$, respectively. Inset:

Variation of anodic peak current vs. square root of scan rate

\section{Chronoamperometric analysis}

Chronoamperometric measurements of levodopa at $\mathrm{V}_{2} \mathrm{O}_{5} / \mathrm{GCE}$ were conducted by adjusting the working electrode potential at $0.4 \mathrm{~V}$ versus $\mathrm{Ag} / \mathrm{AgCl} / \mathrm{KCl}$ $(3.0 \mathrm{M})$ for different concentrations of levodopa (Figure 5) in PBS ( $\mathrm{pH} 7.0$ ), respectively. For electroactive materials (levodopa inthis case) with a diffusion coefficient of $\mathrm{D}$, the Cottrell equation describes current seen for electrochemical reaction at the mass transport limited condition [28].

$$
\mathrm{I}=\mathrm{nFAD}{ }^{1 / 2} \mathrm{C}_{\mathrm{b}} \pi^{-1 / 2} \mathrm{t}^{-1 / 2}
$$


where $\mathrm{D}$ and $\mathrm{C}_{\mathrm{b}}$ respectively represent diffusion coefficient $\left(\mathrm{cm}^{2} \mathrm{~s}^{-1}\right)$ and bulk concentration $\left(\mathrm{mol} \mathrm{cm}{ }^{-3}\right)$. Experimental plots of I versus $\mathrm{t}^{-1 / 2}$ were used with the best fits for various concentrations of levodopa (Figure 5A). Then, the resultant straight lines slopes were drawn against levodopa concentrations (Figure 5B). According to the resultant slope and the Cottrell equation, mean value of $D$ was $4.6 \times 10^{-5} \mathrm{~cm}^{2} / \mathrm{s}$ for levodopa.

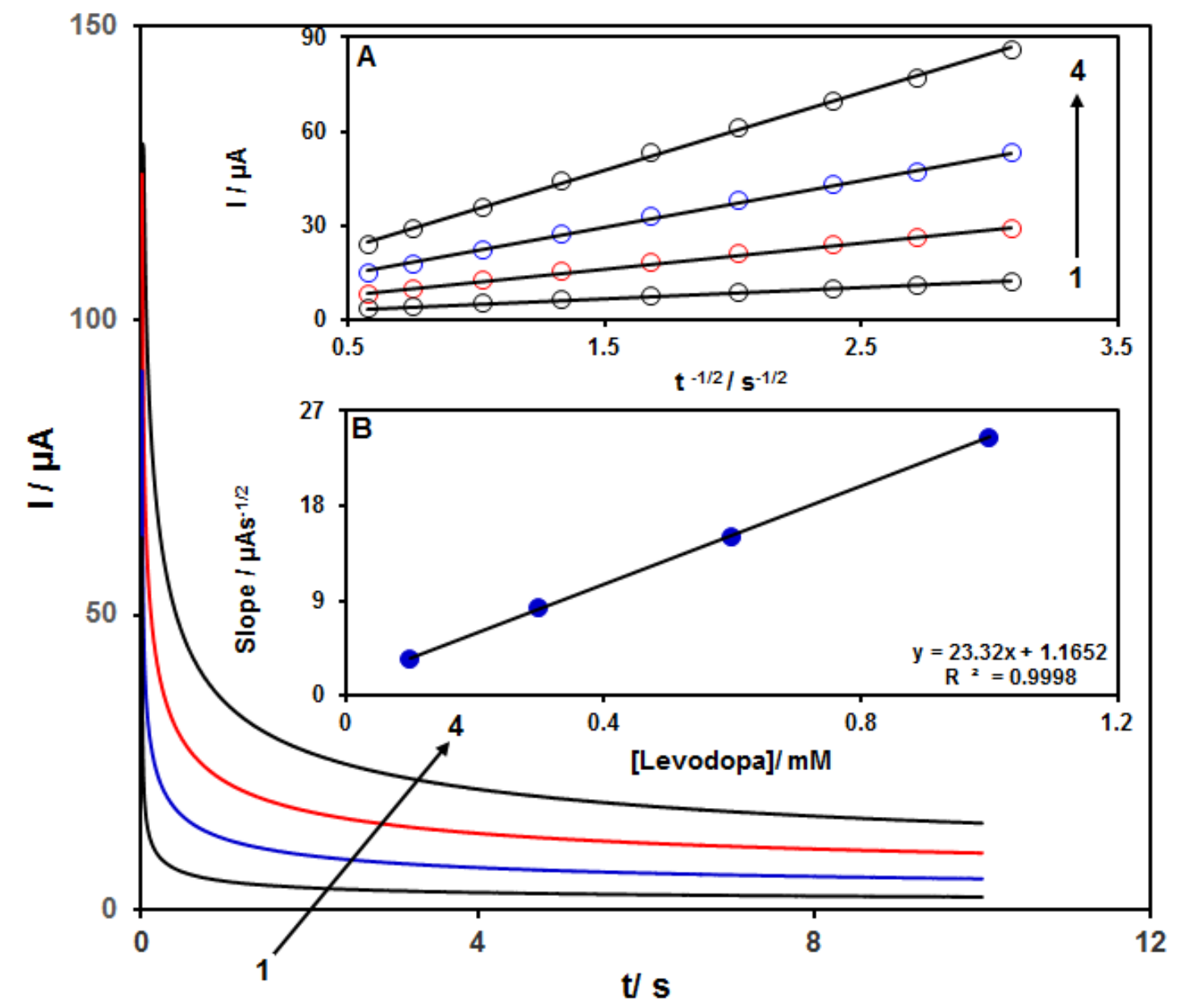

Figure 5. Chronoamperograms obtained at $\mathrm{V}_{2} \mathrm{O}_{5} / \mathrm{GCE}$ in $0.1 \mathrm{M}$ PBS ( $\mathrm{pH} 7.0$ ) for different concentrations of levodopa. The numbers $1-4$ correspond to $0.1,0.3,0.6$ and $1.2 \mathrm{mM}$ of levodopa. Insets: (A) Plots of I vs. $\mathrm{t}^{-1 / 2}$ obtained from chronoamperograms $1-5$. (B) Plot of the slope of the straight lines against levodopa concentrations

\section{Calibration curve and LOD}

The electro-oxidation peak currents of levodopa at $\mathrm{V}_{2} \mathrm{O}_{5} / \mathrm{GCE}$ surface can be applied to define levodopa in the solution. Since the increased sensitivity and more suitable properties for analytical utilizations are considered as the benefits of differential pulse voltammetry (DPV), $\mathrm{V}_{2} \mathrm{O}_{5} / \mathrm{GCE}$ in 0.1 M PBS consisting of different distinct concentrations of levodopa was used to conduct DPV experiments (Figure 6). It was found that the electrocatalytic peak currents of levodopa oxidation at $\mathrm{V}_{2} \mathrm{O}_{5} / \mathrm{GCE}$ surface linearly depended on levodopa concentrations above the range of $0.06-200.0 \mu \mathrm{M}$ (with a correlation coefficient of 0.999 ), while determination limit $(3 \sigma)$ was achieved to be $0.02 \mu \mathrm{M}$. In the case of tryptophan electrocatalytic peak currents of tryptophan oxidation at the 
surface of $\mathrm{V}_{2} \mathrm{O}_{5} / \mathrm{GCE}$ were linearly dependent on the tryptophan concentrations, over the range of $5.0 \times 10^{-6} \quad \mathrm{M}-4.0 \times 10^{-4} \mathrm{M}$ (with a correlation coefficient of 0.999) and the detection limit $(3 \sigma)$ was obtained $2.0 \times 10^{-6} \mathrm{M}$.

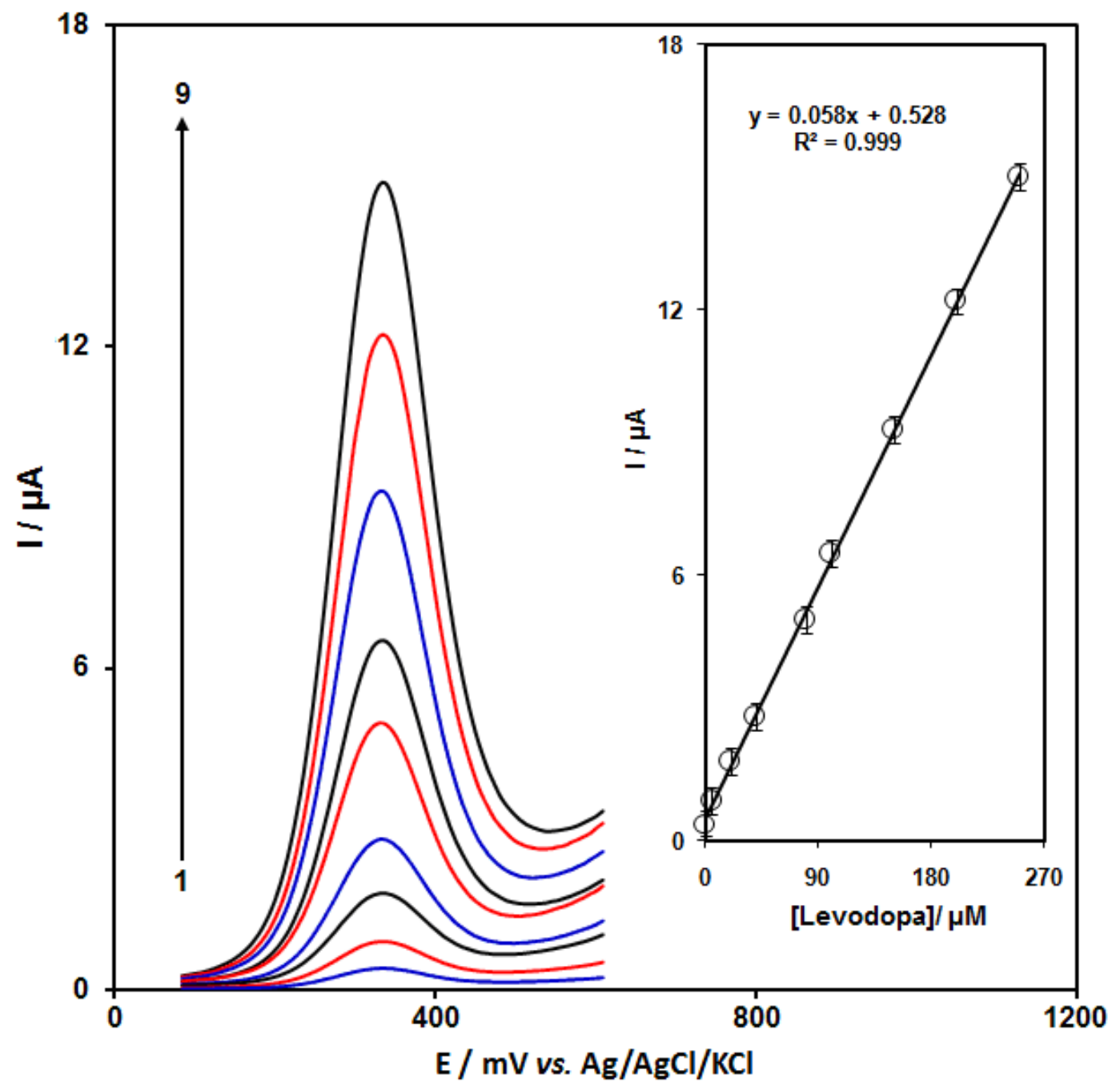

Figure 6. DPVs of $\mathrm{V}_{2} \mathrm{O}_{5} / \mathrm{GCE}$ in $0.1 \mathrm{M}$ PBS (pH 7.0) containing different concentrations of levodopa. Numbers 1-9 correspond to, 0.06, 5.0, 20.0, 40.0, 80.0, 100.0, 150.0, 200.0 and $250.0 \mu \mathrm{M}$ of levodopa. The inset shows the plot of the peak current as a function of the levodopa concentration in the range of $0.06-250.0 \mu \mathrm{M}$
Simultaneous determination of levodopa and tryptophan
To the best of our knowledge, there is no report on using a GCE modified with $\mathrm{V}_{2} \mathrm{O}_{5}$ nanoparticles for determining levodopa and tryptophan. Moreover, due to reality that electrochemical detection of levodopa in the front of tryptophan with the help of un-modified electrodes has the caveat of interventions by tryptophan capacities of the two specimens, it can be regarded a crucial phase. Such a phase has been conducted by simultaneous alterations of analytes concentrations and achieving DPVs (Figure 7). Findings reported certain anodic at 330 and $700 \mathrm{mV}$ for levodopa and tryptophan oxidation, proving using the $\mathrm{V}_{2} \mathrm{O}_{5} / \mathrm{GCE}$, these two analytes can be detected without severe interventions from each another. because of relative adjacent oxidation 


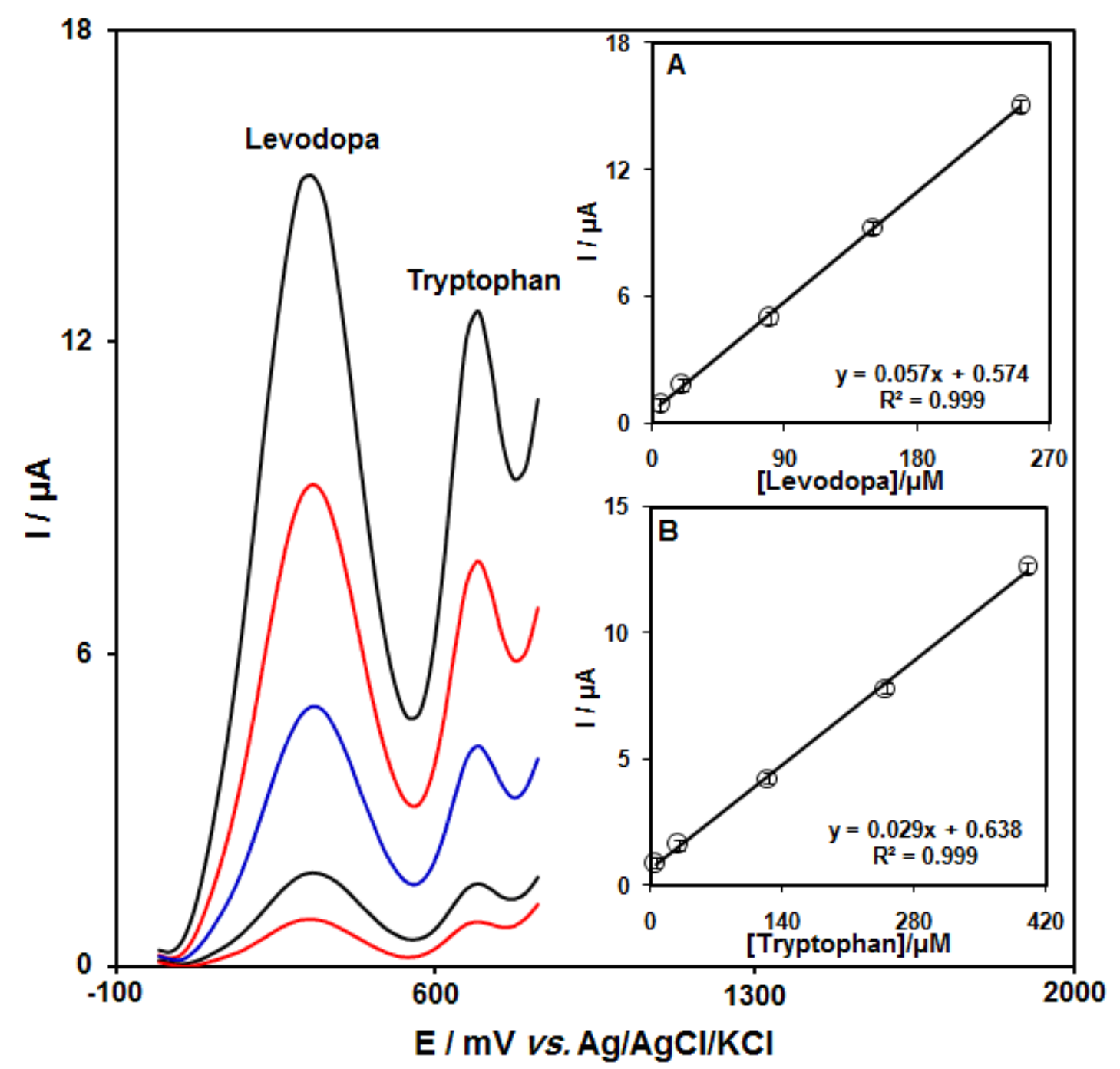

Figure 7. DPVs achieved at $\mathrm{V}_{2} \mathrm{O}_{5} / \mathrm{GCE}$ surface in $0.1 \mathrm{M}$ PBS (pH 7.0) consisting of various concentrations of levodopa and tryptophan. DPVs from internal to external respectively is corresponding to $5.0+5.0,20.0+30.0,80.0+125.0,150.0+250.0$ and $250.0+400.0 \mu \mathrm{M}$ of levodopa and tryptophan. Insets: (a) plot of Ip versus levodopa concentration and (B) plot of Ip versus tryptophan concentration

\section{Analysis of real samples}

To assess the applicability of the modified electrode to determine the levodopa and tryptophan in real samples, the described method was applied to the determination of the levodopa and tryptophan in urine sample. Therefore, the standard addition technique was applied (Table 1). Acceptable recoveries of levodopa and tryptophan were observed, and reproducible results were shown with regard to the mean relative standard deviation (R.S.D.). 
Table 1. Comparison of the efficiency of some modified electrodes used in detection of levodopa

\begin{tabular}{|c|c|c|c|c|c|}
\hline Method & Electrode & Modifier & $\begin{array}{c}\text { Linear } \\
\text { range }(\mu \mathrm{M})\end{array}$ & $\begin{array}{c}\text { Detection } \\
\text { limit }(\mu M)\end{array}$ & Ref \\
\hline Voltammetry & Glassy carbon & rGO & $2.0-100.0$ & 1.13 & 29 \\
\hline Voltammetry & Carbon paste & FCMCNPE & $2.0-500.0$ & 1.2 & 30 \\
\hline Voltammetry & Carbon ionic liquid & Nafion/Co(OH)2-MWCNTs & $0.25-225.0$ & 0.12 & 31 \\
\hline Voltammetry & Glassy carbon & $\begin{array}{c}\text { poly }(2,5 \text {-diamino benzene } \\
\text { sulfonic acid)- } \beta \text {-cyclo dextrine }\end{array}$ & $1.0-200.0$ & 0.41 & 32 \\
\hline Voltammetry & Carbon paste & $\mathrm{BNH} / \mathrm{TiO} 2$ & $2.0-600.0$ & 0.2 & 33 \\
\hline Voltammetry & Glassy carbon & $\mathrm{V}_{2} \mathrm{O}_{5}$ & $0.06-250$ & 0.02 & $\begin{array}{l}\text { This } \\
\text { work }\end{array}$ \\
\hline
\end{tabular}

\section{Conclusion}

In this research study, a $\mathrm{V}_{2} \mathrm{O}_{5} / \mathrm{GCE}$ was developed for the electrochemical simultaneous determination of levodopa and tryptophan. In comparison with the previously reported methods for electrochemical determination of levodopa, the presented method has many advantages, such as simple fabrication, low detection limit and low cost. The $\mathrm{V}_{2} \mathrm{O}_{5} / \mathrm{GCE}$ shows a good electrochemical response for determination of levodopa with the wide linear range between 0.06 and $250.0 \mu \mathrm{M}$ and the limit of detection was calculated to be $0.02 \mu \mathrm{M}$. Moreover, $\mathrm{V}_{2} \mathrm{O}_{5} / \mathrm{GCE}$ operated well in the simultaneous determination of levodopa and tryptophan in real samples with great accuracy and precision.

\section{Acknowledgements}

The authors acknowledge the financial support provided for this project (Project No. 98000293 and ethics code EC/98-29/KNRC) by Neuroscience Research Center, Kerman University of Medical Sciences, Kerman, Iran.

\section{References}

[1] P. Damier, E.C. Hirsch, Y. Agid, A.M. Graybiel, Brain, 1999, 122, 14371448.

[2] B. Kaur, T. Pandiyan, B. Satpati, R. Srivastava, Coll. Surf. B Biointerfaces, 2013, 111, 97-106.
[3] I.A. Mattioli, M. Baccarin, P. Cervini, É.T. Cavalheiro, J. Electroanal. Chem., 2019, 835, 212219.

[4] P. Nagaraja, K.S. Murthy, K.S. Rangappa, N.M. Gowda, Talanta, 1998, 46, 39-44.

[5] I. Molnár-Perl, M. Pintér-Szakács, Anal. Biochem., 1989, 177, 16-19.

[6] W.W. He, X.W. Zhou, J.Q. Lu, J. Chromatogr A, 2006, 1131, 289-292.

[7] K.D. Altria, P. Harkin, M.G. Hindson, J. Chromatogr B: Biomed. Sci. Appl., 1996, 686, 103-110.

[8] M. Doležalová, M. Tkaczykova, $J$. pharmaceut. Biomed. Anal., 1999, 19, 555-567.

[9] S.Y. Lee, K.M. Park, S.H. Jo, H.G. Nam, S. Mun, J. Chromatogr A, 2011, 1218, 1195-1202.

[10] S. Mohammadi, A. Taheri, Z. Rezayati-Zad, Prog. Chem. Biochem. Res., 2018, 1, 1-10.

[11] H. Beitollahi, Z. Dourandish, S. Tajik, M.R. Ganjali, P. Norouzi, F. Faridbod, J. Rare Earths, 2018, 36, 750-757.

[12] G. Vinodhkumar, R. Ramya, M. Vimalan, I. Potheher, A. Cyrac Peter, Prog. Chem. Biochem. Res., 2018, 1, 40-49.

[13] M.R. Ganjali, Z. Dourandish, H. Beitollahi, S. Tajik, L. Hajiaghababaei, B. Larijani, Int. J. Electrochem. Sci, 2018, 13, 2448-2461. 
[14] M. Eldefrawy, E.G.A. Gomaa, S. Salem, F. Abdel Razik, Prog. Chem. Biochem. Res., 2018, 1, 11-18.

[15] S.E. Baghbamidi, H. Beitollahi, S. Tajik, R. Hosseinzadeh, Int. J. Electrochem. Sci., 2016, 11, 1087410883.

[16] Q. He, J. Liu, X. Liu, G. Li, D. Chen, P. Deng, J. Liang, Nanomaterials, 2018, 8, 194-208.

[17] S. Tajik, H. Beitollahi, P. Biparva, J. Serb. Chem. Soc., 2018, 83, 863-874. [18] H. Qi, C. Zhang, Electroanalysis, 2005, 17, 832-838.

[19] Y. Wang, Y. Li, L. Tang, J. Lu, J. Li, Electrochem. Commun, 2009, 11, 889-892.

[20] M. Mazloum-Ardakani, H. Beitollahi, M.K. Amini, F. Mirkhalaf, B.F. Mirjalili, A. Akbari, Analyst, 2011, 136, 1965-1970.

[21] H. Jin, C. Zhao, R. Gui, X. Gao, Z. Wang, Anal. Chim. Acta, 2018, 1025, 154-162.

[22] H.M. Moghaddam, H. Beitollahi, S. Tajik, M. Malakootian, H.K. Maleh, Environ. Monit. Assess., 2014, 186, 7431-7441.

[23] G.C. Han, X. Su, J. Hou, A. Ferranco, X.Z. Feng, R. Zeng, H.B. Kraatz, Sens. Actuators B Chem., 2019, 282, 130-136.

[24] A. Taherkhani, T. Jamali, H. Hadadzadeh, H. Karimi-Maleh, H.
Beitollahi, M. Taghavi, F. Karimi, Ionics, 2014, 20, 421-429.

[25] R. Suresh, K. Giribabu, R. Manigandan, S.P. Kumar, S. Munusamy, S. Muthamizh, V. Narayanan, Sens. Actuators B Chem., 2014, 202, 440-447.

[26] D.P. Nair, T. Sakthivel, R. Nivea, J.S. Eshow, V. Gunasekaran, J. Nanosci. Nanotechnol, 2015, 15, 43924397.

[27] M. Sheikhshoaie, I. Sheikhshoaie, M. Ranjbar, J. Mol. Liq., 2017, 231, 597-601.

[28] A.J. Bard, L.R. Faulkner, second ed., Wiley, New York, NY, 2001.

[29] S.Y. Yi, J.H. Lee, H.G. Hong, J. Applied Electrochem., 2014, 44, 589597.

[30] H. Yaghoubian, H. Karimi-Maleh, M.A. Khalilzadeh, F. Karimi, Int. J. Electrochem. Sci, 2009, 4, 993-1003.

[31] A. Babaei, A.R. Taheri, M. Aminikhah, Electrochim. Acta, 2013, 90, 317-325.

[32] M. Aslanoglu, A. Kutluay, S. Goktas, S. Karabulut, J. Chem. Sci., 2009, 121, 209-215.

[33] M. Mazloum-Ardakani, H. Beitollahi, M.A. Sheikh-Mohseni, H. Naeimi, J. Iran. Chem. Soc., 2012, 9, 27-34.

How to cite this manuscript: Mohammad Reza Aflatoonian, Somayeh Tajik, Behnaz Aflatoonian, Mehri-Saddat Ekrami-Kakhki, Kouros Divsalar, Iran Sheikh Shoaie, Zahra Dourandish, Mahdieh Sheikhshoaie. Simultaneous determination of levodopa and tryptophan using a modified glassy carbon electrode. Eurasian Chemical Communications, 2020, 2(4), 505-515. 